number of candidates who applied for the vacant post of Superintendent of the Laboratory, the Board report that F. E. Reynolds, M.B., Ch.B., Senior Assistant to the Professor of Pathology at Edinburgh University, and formerly Professor of Pathology at the Egyptian Government School of Medicine, Cairo, was unanimously appointed to fill the vacancy, and that Dr. Reynolds's appointment as Lecturer in Neuropathology at the University received the approval of the University Court.

The Board expresses the hope that a closer association may be established between contributing asylums and the Central Laboratory. One of Dr. Revnolds's important duties is to visit periodically the contributing mental hospitals in order that he may advise medical officers as to recent laboratory methods, and at the same time suggest useful lines for research.

For several years past a grant from Treasury funds has been paid by the Medical Research Council to the laboratory for scientific research work. Intimation, however, had been received last year from the Secretary of the Research Council to the effect that an alteration in the method of paying grants had been instituted, and that in future these would only be awarded for special research work receiving the approval of the Committee of the Research Council. Dr. Reynolds has been awarded a grant amounting to $£ 200$ for the current year in respect of his researches into the " Paths of Infection of the Lepto-Meninges."

Until more suitable and convenient premises are found for the Laboratory, Dr. Reynolds occupies a room in the Pathological Department of the Royal Infirmary, Edinburgh, which he has had equipped as an extension to the Laboratory in Frederick Street.

At the Annual Meeting of the Board, Dr. G. Douglas McRae wass unanimously appointed Chairman of the Board in succession to Dr. Skeen, whose term of office had expired, and the Executive Committee was appointed, consisting of Dr. McRae, Chairman; Dr. R. B. Campbell, Honorary Secretary and Treasurer; Drs. Orr, Kerr, Keay, Bruce, Skeen, and Ex-Provost Stark.

\title{
JOINT BOARD OF RESEARCH FOR MENTAL DISEASES, BIRMINCHAM.
}

\section{Annual Report for Year ending March, 1925.}

\section{[ABSTRACT.]}

THE work of the laboratory during the past year has been to develop lines of research upon the basis of endocrine functions; special attention has so far been given to the thyroid gland, and below are given details of the basal metabolism determinations and the analyses of thyroid gland for iodine content. There has been an inquiry into the action of certain hypnotic drugs upon animals with respect to the physiological action and the effect upon the general health and well-being of the animals.

A large amount of routine serological, bacteriological and chemical work has been done for the clinical staff of the Rubery and Hollymoor Hospitals, chiefly from their gynzecological, ear, nose and throat and dental departments.

In view of the probable association between chronic sepsis and disturbed endocrine function the bacteriological work has become part of the researeh, and has occupied the larger propertion of the work of the laboratory.

\section{Basal Metabolis..}

The determination of the basal metabolism in the special respiration chamber has been improved upon both as regards procedure and in respect to refinements of the gas analysis apparatus. The elaboration and perfecting of this apparatus has occupied much time in the laboratory, and much credit is due to Prof. Haldane, F.R.S., and Dr. Graham for valuable assistance and advice.

There have been 60 determinations made of 22 patients and II nurses; and of these 4 patients and I nurse showed metabolism exceeding $\mathrm{I}$ Io per cent. of the standard, the highest being $\mathrm{I} 25$ per cent., and 8 patients and 4 nurses showed metabolism below 90 per cent. of the standard-the lowest, a patient, being just under so per cent. of the standard; the remainder were within 90-r ro per cent. of the figures given in the Harris and Benedict tables for standard metabolism. 
One patient showing defective metabolism was examined on ro occasions and showed only slight variations between 60 per cent. and 70 per cent. of the standard.

\author{
IODINE IN ThYROID GlaND.
}

The investigation of the iodine content of thyroid glands previously carried on at the Pathological Laboratory of the London County Mental Hospital at the Maudsley Hospital has been transferred here and is still in progress.

The chemical results are being correlated as before with the histological investigation in each case.

BACTERIOLOGY.

Dental Dcpt.-Of 25 cases of examination of the tooth-pulp from X-ray or clinically condemned teeth 14 proved sterile by the anaërobic method employed.

Ear, Nose-Throat Dept.-Fourteen cases of sinus infection have been investigated, 3 being clinical cases, by means of a " wash-out" of the sinus or sinuses and I I from swabs taken at autopsy. Streptococci, streptobacilli, diphtheroid and saprophytic organisms were found in most cases.

Gynacological Dept.-Swabs taken from the endocervix by means of special swab tubes showed organisins in 226 out of 338 swabs, i.e., 67 per cent. It is found that diphtheroid organisms largely predominate-e.g., B. Hofmann, B. xerosis, B. flavidum, and another diphtheroid [reference (A)]. Streptococci were quite common, also strepto-bacilli.

Three cases of puerperal sepsis have been investigated, one of which showed at autopsy a thrombosed inferior vena cava with a generalized infection of $B$. lactis aérogenes. Another showed during life a bacteriæmia of a Gram-positive organism occurring in chains of cocci bacteria and threads; from this organism a vaccine was prepared and the patient's brother immunized in preparation for a blood transfusion. Transient good results in this case followed injection of aseptic guinea-pig serum complement in conjunction with polyvalent antistrepto. coccal serum.

Gastro-intestinal.-It was interesting to note in view of the demonstrated sepsis of the mouth and naso-pharynx that 23 of 36 specimens of test-meals showed no free hydrochloric acid.

The examinations of the fxces have shown many varieties of organisms. Streptococci are present in many cases, occasionally in pure culture.

A large number of organisms other than $B$. coli are often found, but which did not fall into the pathogenic groups by reason of their sugar reaction.

$B$. Friedländer of ten occurs in groups of cases, and $B$. cloaca has been found in a blood-culture in one case on two successive occasions, which was suggestive that organisms usually considered " normal," or at least non-pathogenic, may multiply and cause disturbance in debilitated patients such as are commonly met with in mental hospitals.

Other work in progress includes the quantitative estimation of the fat, lipoid and cholesterol content of suprarenal glands obtained at autopsies, and correlations with micro-chemical tests and histological structure.

Some interesting tables follow.

\title{
NOTICES BY THE REGISTRAR.
}

Final Examisation Restlts for the Nursing Certificate, November, 1924.

List of Successful Candidates.

- Passed with distinction.

Bedford.-Hugh Price Searle, John Henry Bruce.

Berks. - Lilian B. Brignall.

Cambridge.-Laura H. Handcock, Florence Summerfield.

Cheshire, Chester County.-John Harry Jones, Nellie Rogers.

Cheshire, Macclesfield.- Harold Bailey, Arthur L. Hatton, Frank Ashley.

Cornwall.-William Champion, N. G. Sheman.

Derby County. - Nina K. Flixon, Mary Ann Tisdall, Edna Lownds, Joseph E. Hall, Charles Morton. 